DOI: https://doi.org/10.29105/gmjmx18.34-2

Artículos

\title{
TRANSFERENCIA DE RELEVANCIA DESDE MEDIOS INDEPENDIENTES CUBANOS HACIA LA PRENSA OFICIAL
}

\section{TRANSFER OF SALIENCE FROM CUBAN INDEPENDENT MEDIA TO THE OFFICIAL PRESS}

\section{José Raúl Gallego Ramos}

Universidad Iberoamericana, México

(D) https://orcid.org/0000-0001-7161-1106

Autor para correspondencia: José Raúl Gallego Ramos, email: josralgallego@gmail.com

\section{Resumen}

El objetivo del presente artículo es comprobar la existencia de transferencia de relevancia a nivel de eventos, atributos y encuadres desde los medios independientes cubanos hacia la prensa oficial, así como identificar las estrategias que emplean los medios oficiales para dar tratamiento a los hechos provenientes de las agendas de la prensa no oficial. Para ello se realizó un monitoreo durante tres meses a medios no oficiales y oficiales para determinar aquellos sucesos que luego de ser publicados por los primeros eran tratados por los segundos. Utilizando como técnica el análisis de contenido cualitativo se comprobó la transferencia de relevancia a nivel de eventos y de la dimensión sustantiva de los atributos; no así en la dimensión afectiva y a nivel de encuadres. Pudo comprobarse el empleo de seis estrategias por parte de los medios oficiales para abordar los eventos provenientes de las agendas de medios independientes. La principal causa de la transferencia de relevancia encontrada es la posición de enfrentamiento de los medios oficiales con un sistema concebido como opuesto y que en la actualidad le disputa la hegemonía informativa y de construcción de sentidos en sectores de público especificos.

Palabras claves: intermedia agenda setting, medios independientes, Cuba, estrategias de tratamiento periodístico, medios oficiales.

\begin{abstract}
This article aimed at verifying the existence of transfer of salience from Cuban independent media to the official press, at level of events, attributes and frames. Equally, this paper deal with identifying official media strategies for treating news of the unofficial press agendas. Official and unofficial media were monitored for three months, in order to achieve the objectives mentioned above. Such monitoring allowed to determine which events were coverage by official media after first been published by unofficial media. Transfer of salience was verified at level of event and the substantive dimension of the attributes due to qualitative content analysis. Transfer of salience
\end{abstract}

Global Media Journal México, 18(34), 18-49, enero - junio 2021. 
was neither verified at level of affective dimension or at level of frames. It could be verified that official media used six strategies to address the events of the independent media agendas. Also, it was found that the main cause of transfer of salience from unofficial media to official media is the confrontation position of the official media facing a system conceived as opposed to it, same which currently disputes the informative hegemony and construction sense in specific public sectors.

Keywords: inter-media agenda setting, independent media, Cuba, journalistic treatment strategies, official media.

Recibido: 10/12/2020

Aceptado: 24/03/2021

\section{Introducción}

El surgimiento de medios independientes dentro de países con sistemas de corte totalitario ha sido un elemento clave para el rompimiento del control estatal sobre la información, característico en este tipo de regímenes.

Independientemente de los contextos, estos medios se desempeñan en la ilegalidad y surgen principalmente para cumplir las funciones sociales que la prensa bajo control estatal en estos países obvia o realiza de manera condicionada.

Los aportes e incidencia de estos medios suelen evaluarse cualitativamente por el servicio prestado a la sociedad, la calidad de su trabajo, la contribución a la erosión del totalitarismo y también por servir como espacios de maduración de sociedades civiles independientes (Doucette, 2013; Skilling, 1989). En términos más cuantitativos suelen ser la diversidad, la extensión y la tirada los indicadores empleados para estudiar el alcance conseguido.

Sin embargo, una de las cuestiones poco atendidas en la literatura ha sido el impacto que tiene el trabajo de estos medios sobre sus contrapartes controladas por el Estado. Debido a que generalmente es limitada la penetración en el público de estos medios, por las difíciles condiciones en que se producen y circulan, un indicador importante de su incidencia es cuando son capaces de colocar ciertos temas en la agenda de los medios oficiales, que sí son consumidos masivamente y reflejan las posiciones del poder político que los controla.

La capacidad de poner ciertos temas en agenda, de llamar la atención sobre ellos, es un indicador incuestionable - tanto a nivel mediático como político- de la relevancia y el empuje de ciertas personas, grupos o instituciones en un contexto determinado.

Cuba es uno de los pocos países que en la actualidad mantiene un sistema sociopolítico de corte totalitario, con control exclusivo de los medios de

Global Media Journal México, 18(34), 18-49, enero - junio 2021. 
comunicación por parte del Estado-Partido y prohibición constitucional del surgimiento de medios independientes a dicho control. Sin embargo, desde finales de los ochenta y sobre todo en la última década con la entrada de Internet, han surgido y se han fortalecido un creciente número de medios que desafían el monopolio estatal sobre la información y la comunicación.

La calidad periodística y la contribución de estos medios al fomento de valores democráticos han sido reconocidas internacionalmente. Estudios previos han analizado su características formales y estilísticas, agendas temáticas, financiamiento, modelos de gestión, condiciones de producción informativa, roles profesionales, entre otros temas. Sin embargo, la cuestión de su incidencia sobre los contenidos de los medios oficiales es algo que se comenta cada día más dentro del gremio, pero sin que existan estudios que trabajen la evidencia empírica que permita afirmarlo.

Por ello, tomando como base teórica el concepto de intermedia agenda setting (McCombs, 2014), la presente investigación tiene como objetivos: 1) determinar si existen relaciones de transferencia de relevancia desde los medios independientes cubanos hacia la prensa oficial controlada por el Estado-Partido; y 2) establecer las estrategias empleadas por los medios oficiales para tratar los hechos asumidos desde las agendas de los medios independientes.

Para ello se realizó un monitoreo de las publicaciones de medios no oficiales y oficiales entre el 1ro de octubre y el 31 de diciembre de 2019, para determinar aquellos hechos que luego de ser informados por los primeros, aparecían en los segundos durante un lapso temporal de un día o más. La técnica de investigación empleada fue el análisis de contenido cualitativo.

Los resultados de esta investigación aportan evidencia sobre un área poco estudiada tanto a nivel global como en el caso específico de Cuba: la transferencia de relevancia desde medios independientes hacia medios oficiales en sistemas totalitarios. Los resultados obtenidos contribuyen a una valoración más amplia de los medios no oficiales y de la incidencia de su trabajo a un nivel más concreto y sistémico.

\section{Diseño teórico}

Las relaciones entre las agendas de diferentes medios es una de las áreas de estudio dentro de la investigación de Newsmaking y Agenda Setting. A finales de la década de 1970, Gans (2004) se refirió a la competencia entre periodistas y los propios medios como uno de los factores que condiciona los valores noticia e incide sobre los contenidos de las organizaciones periodísticas. Por un lado, está la lucha por la primicia, pero a su vez, "la competencia establece expectativas mutuas, lo cual trae como resultado, que los gatekeepers pueden elegir determinadas historias porque esperan que su rival las elija" (Gans, 2004, p. 177).

De esta forma, se van estructurando relaciones de coincidencia entre las agendas de diferentes medios, reforzadas por culturas 
periodísticas comunes que comparten nociones semejantes de los valores noticia, a la par que se establecen paradigmas de periodismo que funcionan no solo como referentes para el tratamiento de la información, sino también para la selección.

Resultados similares se encontraron pocos años después desde los estudios de agenda. Whitney y Becker (1982) comprobaron a través de un experimento con 46 editores que las noticias de agencias funcionaban como un referente a la hora de determinar las proporciones en que determinados temas debían aparecer en sus medios. Otros autores también documentaron de manera sistemática relaciones de transferencia de temas entre agendas de diferentes medios (Atwater et al., 1987; Kai, 2010; Miller, 1991; Reese y Daniellan, 1989), por lo que este efecto de intermedia agenda setting fue incorporado al cuerpo teórico de la investigación de establecimiento de agenda, solo que, de una manera más simplificada, la explicación se concentró en la "influencia sustancial" que los medios informativos de élite ejercen sobre la agenda de los otros medios (McCombs, 2014).

Sin embargo, dentro de los propios estudios de agenda se ha encontrado evidencia empírica que demuestra que medios más pequeños, especializados, alternativos y redes sociales pueden en ocasiones introducir determinados temas en las agendas de las grandes organizaciones mediáticas (Billard, 2019; Conway et al., Tsetsi, 2017; Mathes y Pfetsch, 1991; Meraz, 2011; Valenzuela et al., 2017). En estos casos, Song (2007) habla de "inter-media agenda initiator" (p. 5).
La transferencia de relevancia entre agendas mediáticas puede darse a nivel de eventos y objetos. Según Shaw (citado en Rogers y Dearing, 1988) los primeros son aquellos sucesos discretos limitados por el espacio y el tiempo, y los segundos son la atención acumulativa a una serie de eventos relacionados que juntos pueden formar parte de una categoría más amplia. Es frecuente que un acontecimiento concreto (evento) pase de una agenda a otra, pero también se ha registrado que temas más amplios (objetos) son desarrollados en medios específicos y luego ganan la atención de otras agendas mediáticas más amplias (Strodthoff et al., 1985).

Estas relaciones de transferencia también han sido encontradas a nivel de atributos (Billard, 2019; Denham, 2014, 2019), entendidos como la variada gama de propiedades y rasgos más sobresalientes que caracterizan a un tema $y$ completan su imagen; poseen una dimensión sustantiva (subtemas) y una afectiva (valoraciones positivas, neutras o negativas). Los medios no sólo suelen prestar atención a aquellos temas priorizados por su competencia, sino que en ocasiones suelen asimilar los subtemas y valoraciones con que fueron abordados por otra organización mediática y hasta adoptar los mismos encuadres (Neuman et al., 2014; Wang y Guo, 2018). El acto de encuadrar se entiende como:

Escoger algunos elementos de la realidad
percibida y ensamblar una narrativa que
destaca conexiones entre ellos para promover
una explicación particular. Los marcos 
completamente desarrollados efectúan típicamente cuatro funciones: definición de problema, análisis causal, juicios morales y promoción de soluciones (Entman, 2007, p. 164).

En los casos en que un medio asimila los encuadres provenientes de otro, suele deberse a la influencia de los referentes descritos por Gans (2004), a la identificación ideológica entre medios con posiciones políticas y líneas editoriales semejantes o incluso, a cuestiones prácticas de las propias rutinas productivas que llevan a que una organización mediática de menos recursos reproduzca a veces de manera inconsciente, los enfoques provenientes de grandes medios.

Sin embargo, también suele suceder que la transferencia ocurra a nivel de objetos, eventos y hasta algunos atributos (en su dimensión sustantiva), pero no de encuadres. En estos casos, se puede estar en presencia del resaltado de diferentes aspectos de la noticia (ya sea de manera intencional o no) o de la contraposición entre visiones antagónicas o divergentes de un mismo hecho, que tienen como trasfondo cuestiones de tipo político-ideológicas.

\section{Medios oficiales y sin reconocimiento oficial en Cuba}

Cuba es uno de los pocos países en el mundo que en su Constitución limita las formas de propiedad que pueden asumir los medios de comunicación (República de Cuba, 2019), para así otorgarle un estatus legal al monopolio estatal-partidista sobre los medios. Sin embargo, a partir de la década de los ochenta del pasado siglo y fundamentalmente luego del año 2010, fueron apareciendo un grupo de medios de comunicación en formato impreso y digital al margen del control gubernamental y sin el reconocimiento de este.

En la actualidad, la ecología mediática cubana se conforma por un sistema de medios en todos los formatos subordinados al control del Estado y el Partido Comunista de Cuba (al cual se le denominará oficial o estatal) y un grupo de medios mayormente digitales o en formato de boletines impresos, que no cuentan con reconocimiento legal e independientes al control directo del Estado-Partido, a los cuales se les denomina indistintamente alternativos, independientes o no oficiales.

De manera general, el sistema de medios oficiales, tal y como existe en la actualidad, adquiere sus rasgos estructurales a mediados de la década de 1960. Se encuentra distribuido por todo el país e incluye todos los soportes mediáticos, con medios que operan desde el nivel de comunidades hasta el internacional.

Es un sistema que copia sus rasgos estructurales principales del modelo de prensa soviético (García Santamaría, 2018; Padilla et al., 2017), carente de autonomía porque constituye un subsistema del sistema político (García Luis, 2004), caracterizado por la centralización, la verticalidad y la unidireccionalidad de los flujos informativos (Salazar, 2017) y cuyas agendas se encuentran en gran medida distanciadas de las agendas públicas (Gallego y Rosabal, 2013; Muñiz y Castillo, 2017). 
Los medios que han surgido fuera de este sistema comenzaron a aparecer a finales de la década de 1980 con algunas características similares a publicaciones samizdat de Europa del Este. Con la llegada de Internet, varios de estos medios se han replicado en la red y también surgieron otros nuevos, gestados y mantenidos en su mayoría por jóvenes graduados de Periodismo y otras especialidades en las universidades cubanas. Estos medios subsisten en condiciones de ilegalidad, funcionan con recursos propios y fondos provenientes en su mayoría del extranjero, y sus agendas se nutren fundamentalmente de aquellos temas y enfoques que son obviados o poco atendidos por los medios oficiales. Entre ellos pueden mencionarse a Cubanet, 14ymedio, ADNCuba, Diario de Cuba, El Estornudo, El Toque, Periodismo de Barrio, Tremenda Nota, Yucabyte, Inventario, Hypermedia Magazine, Rialta, entre otros.

En la actualidad medios oficiales y sin reconocimiento oficial conviven en un ambiente que se mueve entre el desconocimiento y la tirantez. El gobierno cubano considera a estos últimos como parte de una estrategia externa para subvertir el orden sociopolítico del país y los clasifica como privados, con intencionalidad hipercrítica y desmovilizadora (Comité Ejecutivo del Consejo de Ministros, 2018).

La Unión de Periodistas de Cuba (UPEC), organización gremial paraestatal, única permitida en el país, replica este discurso, expulsa de sus filas a quienes colaboran con estos medios y mantiene una posición hostil hacia los mismos, a pesar de que entre muchos periodistas jóvenes existen buenas relaciones sin importar el tipo de medio para el que trabajen. Por su parte, los medios sin reconocimiento oficial con frecuencia critican el trabajo de la UPEC y a los medios oficiales por su subordinación a los designios partidistas por encima de los intereses gremiales y del compromiso del periodismo con valores públicos y democráticos.

Aunque Cuba continúa siendo de los países de la región con menos acceso y libertad en Internet (Freedom House, 2021), el aumento de las tasas de conectividad en los últimos años ha posibilitado que crezca el número de personas que desde la Isla consume los medios independientes, como muestran las cifras que algunos de ellos hacen públicas en sus redes. No obstante, aún existen grandes masas poblacionales que no tienen acceso a Internet, de ahí que la aparición en los medios oficiales de noticias puestas en la agenda por los medios independientes sea una forma de que estos sucesos lleguen a un mayor número de personas, pero también de que puedan ser asumidos por algunos, al no tener otras fuentes de contraste, desde la visión ofrecida por la oficialidad.

\section{Metodología}

Aunque las relaciones entre agendas mediáticas no ocurren de manera unidireccional, el objetivo de este estudio es comprobar si existe transferencia de relevancia de eventos, atributos y encuadres, desde los medios sin reconocimiento oficial hacia los medios oficiales. En la dirección contraria, la pregunta no posee igual relevancia, ya que al tener

Global Media Journal México, 18(34), 18-49, enero - junio 2021. 
los medios oficiales mucho mayor alcance y consumo, y ser voceros además del poder político, es normal que constantemente los medios no oficiales se hagan eco de sus agendas, generalmente desde una perspectiva crítica.

La agenda mediática se entiende como esa parte de la realidad que un medio destaca en forma de objetos, eventos, atributos y encuadres. Se materializa en la selección, jerarquización y tratamiento periodístico de temas y acontecimientos que responden a los intereses del medio. Por su parte, la transferencia de relevancia entre agendas mediáticas se define como el proceso mediante el cual los objetos, eventos, atributos y encuadres destacados por un medio son adoptados por otra organización mediática.

La transferencia de relevancia será estudiada a tres niveles: de eventos, de atributos y de encuadres. El marco temporal de esta investigación no permite estudiar la transferencia de relevancia de objetos, pues debido al carácter acumulativo de estos, se necesita trabajar con períodos de tiempo muy extensos que faciliten observar los movimientos temáticos que trasciendan la aparición puntual de un hecho determinado. La estrategia metodológica seguida fue la siguiente:

1. Entre el 1 de octubre de 2019 y el 31 de diciembre de 2019 se realizó un seguimiento de las noticias publicadas por nueve medios no oficiales, todos en formato digital: 14ymedio, ADNCuba, CiberCuba, Cubacomenta, Cubanet, Cubanos por el Mundo, CubitaNow, Diario de Cuba y Periódico Cubano.
Además de su perfil generalista, una parte de estos medios fueron seleccionados por ser de los que cuentan con mayor cantidad de periodistas y colaboradores dentro de la Isla y otros por su capacidad para replicar con rapidez las noticias aparecidas en otros medios o redes sociales sobre temas cubanos, lo cual permite cubrir de manera amplia el espectro noticioso sobre el país.

2. Paralelamente, se realizó un monitoreo en medios estatales para identificar cuáles eventos resaltados por los medios sin reconocimiento oficial eran abordados en los medios oficiales con un desfase temporal de un día o más. Se encontraron réplicas en los medios Granma, Cubadebate, Juventud Rebelde, Prensa Latina, Cubahora, CubaSí, Jit, Las Razones de Cuba, el Noticiero de la Televisión Cubana (NTV), el canal de Youtube de Qva en Directo, el programa Hola Habana, del Canal Habana y la sección Así como te digo, del Canal Caribe.

3. Los eventos presentados por los medios independientes $\mathrm{y}$ asumidos con posterioridad por los medios oficiales fueron sometidos a un análisis de contenido cualitativo (Schreier, 2012), para comparar el tratamiento en cuanto a atributos y encuadres.

4. Por último, se realizó un análisis de las estrategias que emplean los medios 
oficiales para dar tratamiento a los hechos destacados con anterioridad por los medios independientes.

En total se analizaron 108 textos publicados en medios independientes digitales y 36 trabajos periodísticos publicados en medios oficiales en formato impreso, digital y televisivo.

\section{Resultados}

\section{Transferencia de relevancia}

Fueron 16 los hechos abordados por los medios independientes que luego pasaron a formar parte de la agenda de medios oficiales en el período estudiado. Estos fueron:

\section{a) Encarcelamiento del líder opositor}

\section{José Daniel Ferrer}

Durante todo el mes de octubre y noviembre, los medios no oficiales cubanos informaron $y$ denunciaron la detención de José Daniel Ferrer, líder de la agrupación opositora Unión Patriótica de Cuba (UNPACU). La noticia se alimentó con las declaraciones a su favor realizadas por organismos internacionales y políticos de Estados Unidos y la Unión Europea.

Luego de casi dos meses de silencio, los medios oficiales lanzaron al unísono una campaña sobre el caso de Ferrer. Comenzó con un editorial publicado en Granma el 20 de noviembre con título "Nueva campaña de calumnias de EE. UU. contra
Cuba", a lo cual prosiguió un material audiovisual en el NTV que dio pie a una gran cantidad de textos sobre el tema en medios nacionales y provinciales.

\section{b) Muerte de bebé por vacunación}

El 10 de octubre comenzó a circular en las redes el rumor de que el día antes había muerto en La Habana una niña de dos años y que otros se encontraban graves después de recibir una vacuna. Al día siguiente, la mayoría de los medios no oficiales cubanos y varios internacionales se hicieron eco de la noticia. Ante la repercusión y la crítica al silencio de los medios oficiales, el día 12 de octubre el diario Granma publicó una escueta nota del Ministerio de Salud Pública que en 265 palabras informaba sobre el caso y la muerte de la menor. Cuatro días después, el medio oficial Cubadebate publicó un extenso reportaje sobre el tema y el 21 de octubre Granma publicó un reportaje sobre los logros del Programa Nacional de Inmunización. El 9 de noviembre Granma publicó en su última página los resultados de la investigación, la cual dio como causa de las reacciones "violaciones de las normas establecidas en la vacunación" (MINSAP, 2019, p. 8) y Cubadebate publicó un comentario sobre el tema.

\section{c) Hacinamiento en hospital de Baracoa}

A fines de octubre, una madre publicó en redes sociales sobre la situación de hacinamiento y escasez de medicamentos en el hospital del municipio de Baracoa, en el oriente de Cuba. Varios medios no oficiales reportaron sobre la denuncia, usando como base la publicación en Facebook. 
Sin hacer referencia a este hecho, dos días después Cubadebate publica un texto sobre ese hospital en el cual su director menciona que tienen cobertura de camas y que, a pesar de las carencias provocadas por el bloqueo de Estados Unidos, no han dejado de funcionar y brindar un buen servicio. El artículo fue realizado por una periodista que confiesa no haber tenido "la oportunidad de ir todavía a Baracoa" y que las entrevistas las realizó online (Valdés, 2019).

\section{d) Declaraciones del historiador del Ballet Nacional de Cuba}

El 29 de octubre el espacio televisivo "Con dos que se quieran" transmitió una entrevista a Miguel Cabrera, Historiador del Ballet Nacional de Cuba. En la misma, para resaltar el trabajo de esa institución, Cabrera utilizó una serie de expresiones racistas y homofóbicas que causaron inmediata molestia en parte de la población cubana y fueron denunciadas en medios no oficiales del país. Por esos días, fue sin dudas una de las noticias con más visibilidad en las redes.

Casi un mes después, un artículo del diario Granma que defendía "la esencia antirracista de la Revolución cubana", hizo alusión tangencialmente a las palabras de Cabrera. En una oración, se menciona que no pueden pasarse por alto declaraciones como estas "porque hay cosas que cuando se toman a la ligera, impensada e irresponsablemente, laceran sensibilidades" (de la Hoz, 2019). Al día siguiente, el mismo diario informó que en una reunión del Consejo de Ministros se anunció la creación de un
Programa Nacional contra el racismo y la discriminación racial (Martínez, 2019).

\section{e) Recogida de perros y protesta de protectores}

A inicios de noviembre, múltiples medios cubanos no oficiales y extranjeros reportaron denuncias de recogidas y sacrificios masivos de perros callejeros en La Habana y Santiago de Cuba, producto de la visita del rey de España a Cuba. Las denuncias fueron secundadas por varias figuras públicas del sector del arte en el país, lo cual dio mayor realce a la noticia. El día 11 de noviembre, ante la continuidad de las recogidas, un grupo de protectores protagonizaron una protesta en La Habana, ante la sede de Zoonosis, donde recluían y sacrificaban los animales. Este hecho tuvo gran visibilidad en la prensa independiente y las redes sociales, ya que en Cuba no son frecuentes y se encuentran prohibidas de facto las manifestaciones no convocadas por el Estado.

El impacto que tuvo este hecho hizo que varios medios oficiales hicieran alusión al mismo, negando el sacrificio de los perros y tratando de mostrar una posición de interés por parte del Gobierno hacia la protección animal.

\section{f) Detención de funcionarios cubanos en Bolivia}

En medio del proceso que provocó la salida del poder de Evo Morales, un grupo de cuatro cubanos fueron detenidos en Bolivia portando maletines con grandes sumas de dinero. Los detenidos eran miembros de la misión médica cubana y alegaron que el dinero era para el pago de los colaboradores. Sin embargo, las autoridades bolivianas los acusaron de financiar protestas contra el nuevo gobierno. Desde el día 14

Global Media Journal México, 18(34), 18-49, enero - junio 2021. 
de noviembre en la mañana, medios del país sudamericano y cubanos no oficiales reportaron sobre el incidente resaltando estos elementos.

Al día siguiente en la tarde el canciller cubano Bruno Rodríguez se pronunció en Twitter y a partir de entonces los medios cubanos, luego de un día de silencio, reportaron el hecho y dieron seguimiento al posterior regreso de los detenidos.

\section{g) Cancelación de concierto de Haila en Miami}

Grupos de cubanos radicados en Estados Unidos organizaron un boicot a la cantante popular Haila María Mompié por sus manifestaciones de afecto hacia Fidel Castro. La presión en redes sociales liderada por el influencer Alex Otaola, concluyó con la cancelación de su concierto del 14 de noviembre en Miami. Medios del sur de la Florida y cubanos no oficiales replicaron la información desde el 12 de noviembre haciendo énfasis en los motivos dados por el alcalde de Miami para declararla persona "non grata" en esa ciudad.

El 21 de noviembre, Granma publicó un texto dedicado a la cantante. Luego de exaltar la carrera musical de Haila, destaca la coherencia entre sus acciones y su obra, y critica a esa parte del exilio cubano que "no le perdonan su beso y su canto a Fidel" (Acosta, 2019).

\section{h) Reapertura del mercado Cuatro Caminos}

La muy promocionada reapertura del Mercado de Cuatro Caminos en La Habana terminó con su cierre ese mismo día producto de los destrozos causados por los consumidores. Los medios no oficiales dieron cuenta del hecho desde el mismo 16 de noviembre, enfatizando en los desórdenes ocurridos y la presencia policial.

Al día siguiente en la tarde, Cubadebate reprodujo una nota de la corporación que administra el mercado anunciando que sería cerrado hasta la próxima semana. Ante la falta de detalles los usuarios comenzaron a reclamar una mayor información. Al día siguiente el tema fue abordado en un comentario en la emisión estelar del NTV y otras emisiones en días posteriores. El 19 de noviembre Cubadebate publicó un reportaje sobre el tema. Dos semanas después, el Canal Caribe volvió a abordar el tema.

\section{i) Eliminación del CUC en los aeropuertos}

El 20 de noviembre varios medios no oficiales dieron la noticia de que se había eliminado el empleo de pesos cubanos convertibles (CUC) en el interior de los aeropuertos del país. La mayoría de los medios no oficiales que tocaron el tema enfatizaron en la molestia que dicha medida provocaba a los viajeros.

Tres días después el NTV abordó el tema refiriendo a los "criterios generados en las redes sociales" (Alonso, 2019) al respecto. A diferencia de los medios no oficiales, aquí emplearon entrevistas a pasajeros y funcionarios que recalcaron que era una medida correcta, que no generaba dificultades y que estaba en consonancia con las normas internacionales. Este tema no fue abordado en ningún otro medio oficial.

\section{j) Bebé abandonado}

Los medios no oficiales reportaron el 25 de noviembre la publicación de una usuaria de Facebook que refería el hallazgo de un bebé recién 
nacido abandonado en La Habana. En las publicaciones se refería que se desconocían las causas del suceso y se contraponía la actitud de la madre a la de los doctores que atendieron a la niña y la sacaron de peligro.

Cuatro días después el periódico Juventud Rebelde publicó un comentario sobre el tema. Partía de la conmoción provocada por el hecho en redes sociales. Enfocaba la noticia en la protección ofrecida por los trabajadores del sistema de salud cubano, a la vez que calificaba el hecho como "detestable", "vergonzoso", "salvajismo", pero llamaba a "no juzgar anticipadamente a una persona de la cual no conocemos detalles" (Peña, 2019).

\section{k) Gira de Carlos Varela}

El cantautor Carlos Varela anunció en su perfil de Facebook que no podría ofrecer en la fecha anunciada una gira nacional, pues las autoridades de Cultura le informaron que en este momento el país no se encontraba en condiciones desde el punto de vista económico. El mismo día 29 de noviembre varios medios no oficiales encuadraron la noticia en la cancelación de la gira producto de problemas económicos, pero también hicieron alusión a episodios de censura sufridos por el músico en anteriores ocasiones.

El 18 de diciembre, Granma y Cubadebate publicaron un texto que se refería a comentarios dañinos en las redes y especificaba que la gira no había sido cancelada, sino pospuesta. Desmentía la existencia de algún tipo de censura contra Varela y aseguraba que sería reprogramada la gira una vez que se resolviera la situación del país.

\section{l) Alusión de Vargas Llosa a Cuba en entrevista}

El Nobel de Literatura Mario Vargas Llosa otorgó una entrevista donde, entre otros temas, comentó que "el pueblo cubano está a punto de dar una sorpresa" y se refirió al gobierno cubano como dictadura y mancha terrible en Latinoamérica. Este encuadre fue reproducido por los medios no oficiales cubanos.

Cinco días después, la Unión de Artistas y Escritores de Cuba (UNEAC) emitió una declaración publicada en Cubadebate, Granma y Juventud Rebelde en la cual rechazaba "los insultos y mentiras de Vargas Llosa", lo acusaba de estimular un levantamiento interno en Cuba y sentenciaba que la sorpresa del pueblo cubano era ser más fiel al socialismo y a Fidel (UNEAC, 2019).

\section{m) Sepelio del campeón olímpico Jorge Hernández}

Luego del entierro del campeón olímpico de boxeo Jorge Hernández, su hijo criticó en Facebook a las autoridades deportivas del país por no garantizar un ataúd de calidad para su padre. Los medios no oficiales reportaron la crítica y resaltaron las partes de la publicación que hacían referencia a la falta de atención y la traición a una gloria deportiva del país.

Al día siguiente, el sitio digital JIT publicó la respuesta de las autoridades deportivas, replicada por la agencia Prensa Latina, la cual comenzaba expresando: "Con profundo pesar hemos apreciado en las últimas horas los comentarios aparecidos en la red social Facebook vinculados a las honras fúnebres y el sepelio dado en días pasados a Jorge Hernández" (INDER, 2019). 


\section{n) Eliminación del CUC}

Desde que fue anunciada por Raúl Castro la inminencia de la unificación monetaria, son frecuentes los rumores que anuncian el esperado "día cero". A finales de 2019 una serie de sucesos se hilvanaron y dieron fuerza a la suposición de que ocurriría a inicios de 2020. La teoría cobró fuerza cuando a mediados de diciembre el medio no oficial Cibercuba (Cabrera, 2019) publicó una supuesta filtración que aseguraba la inminencia de la medida, el establecimiento de una tasa de cambio mayor a la existente en ese momento y una reforma salarial.

Tres días después Cubadebate (2019) publicó una corta nota con información de la agencia Prensa Latina, luego replicada en Granma, en la cual el Ministro de Economía “desmintió versiones de prensa sobre un cambio inminente de la tasa del dólar con respecto al peso nacional de uno por 50.” En la nota publicada en Granma se habla de "ciertas manipulaciones" sin mencionar el tema de las "versiones de prensa".

\section{o) Salida del actor Andy Vázquez del programa}

\section{Vivir del Cuento}

A mediados de diciembre, varios medios no oficiales replicaron el rumor de que el popular actor Andy Vázquez había sido expulsado del programa humorístico Vivir del Cuento por cuestionas políticas, y que se radicaría en Miami. Con la no aparición del actor en el capítulo de ese programa estrenado el 30 de diciembre, la noticia volvió a tomar fuerza. A las denuncias de censura se sumó las muestras de desacuerdo entre el público que exigía la restitución inmediata de Vázquez y pedía al resto del elenco que presionara en apoyo al humorista.

En medio del rumor de la expulsión de Vázquez, Cubadebate publicó el 26 de diciembre un texto donde anunciaba la salida al aire de nuevos capítulos, pero sin tocar el tema de la expulsión de Andy Vázquez y usando una foto en la que aparecía este actor junto al resto del elenco (Armas, 2019). No fue hasta el 3 de enero, que haciendo uso de un canal de Youtube de reciente creación (Qva en Directo, 2020), el director del canal Cubavisión dijo que no estaba sancionado, sino que se había "tomado una decisión". La causa fue "el uso de su personaje en función de un criterio personal". Un artículo publicado días después en Cubadebate confirmó esta misma causa de la sanción, calificó la actuación de Vázquez como lamentable e irresponsable y pidió que no se continuara avivando la polémica para evitar males mayores al programa (Armas, 2020).

\section{p) Presentación de Gente de Zona en concierto en Miami}

El 23 de diciembre, medios del sur de la Florida y no oficiales cubanos informaron que había sido cancelada la presentación en Miami del grupo Gente de Zona. La suspensión se atribuyó a las peticiones de cubanos residentes en la ciudad quienes criticaron la vinculación del dúo con el régimen cubano. La cancelación se presentó como un triunfo del exilio.

Cuatro días después, tres medios oficiales cubanos publicaron dos textos diferentes en los que se presentaba el hecho como una consecuencia del aumento del bloqueo norteamericano hacia Cuba, como un ataque al intercambio cultural entre ambos

Global Media Journal México, 18(34), 18-49, enero - junio 2021. 
países y fue calificado de terrorismo cultural, intolerancia y medidas para complacer a minorías. Estos textos solo fueron publicados en medios digitales.

Los 16 hechos abordados primero en medios no oficiales y luego en la prensa estatal pueden clasificarse como eventos. El objeto con mayor cantidad de eventos fue Cultura (Tabla 1). Luego le siguieron otros tres objetos (Problemas sociales, Salud pública y Economía) que investigaciones anteriores (Gallego y Rosabal, 2013; Muñiz y Castillo, 2017) han encontrado en las agendas mediáticas cubanas, aunque con atributos diferentes.

\section{Tabla 1}

Objetos en los que se ubican los eventos que pasaron desde las agendas de medios independientes hacia los medios oficiales

\begin{tabular}{cc}
\hline Objeto & Evento \\
Cultura & $\begin{array}{c}\text { Gira Varela } \\
\text { Concierto Haila } \\
\text { Sanción Andy } \\
\text { Presentación GdZ }\end{array}$ \\
\hline Problemas sociales & $\begin{array}{c}\text { Bebé abandonado } \\
\text { Apertura mercado } \\
\text { Historiador Ballet }\end{array}$ \\
\hline Salud pública & Muerte Bebé \\
& Hospital Baracoa \\
\hline Economía & $\begin{array}{c}\text { Eliminación CUC } \\
\text { CUC aeropuertos }\end{array}$ \\
\hline Oposición política & Prisión Ferrer \\
& Entrevista Vargas Llosa \\
\hline Medio ambiente & Recogida perros \\
\hline Política exterior & Detenidos Bolivia \\
\hline Deporte & Sepelio Hernández \\
\hline
\end{tabular}

Es llamativo la aparición dos veces de eventos que pueden ubicarse en el objeto Oposición política; un tema que suele ser poco tratado en la prensa cubana y que generalmente aparece asociado a crisis externas que fuerzan a Cuba a brindar una respuesta.

Como se puede observar, en estos temas existe un trasfondo o matiz político que disputa las visiones positivas del país o la línea argumentativa sobre hechos específicos que se enuncian desde el discurso oficial.

En todos los casos, los temas fueron abordados en los medios oficiales en un lapso temporal igual o mayor a un día después de que fueron tratados por la prensa independiente. Esto demuestra que efectivamente existió transferencia de relevancia de eventos desde los medios no oficiales hacia los medios subordinados directamente a la línea informativa trazada por el PCC. No obstante, en algunos casos no puede afirmarse de manera definitiva que estas apariciones sean producto de la transferencia de relevancia temática, ya que pudieran deberse a la tradicional lentitud de la prensa oficial cubana producto de su falta de autonomía.

Aunque no existan investigaciones previas que permitan un punto de comparación, puede decirse que respecto a épocas anteriores ha aumentado la tendencia a "responder" y a tocar temas que aparecen publicados en medios no oficiales. Entre los factores que pudieran incidir en ello está el crecimiento del acceso a Internet y a las nuevas tecnologías, lo cual contribuye a que las noticias se conozcan, diseminen y generen estados de opinión aun cuando no hayan sido reflejadas por la prensa oficial. Ello ha traído consigo un incremento de la

Global Media Journal México, 18(34), 18-49, enero - junio 2021. 
conciencia, dentro del gremio y parte del poder político cubano, de que no informar un hecho no implica, en la actualidad, que sea desconocido (Garcés, 2013).

No quiere decir que hayan dejado de existir las zonas de silencio dentro de la prensa cubana. Una investigación sobre vacíos informativos realizada de manera paralela a este estudio por su autor mostró que en el período analizado fueron más los acontecimientos develados por medios independientes omitidos por la prensa oficial que aquellos que sí fueron tratados.

En cuanto a los atributos, también hubo transferencia de relevancia, fundamentalmente en la dimensión sustantiva (Tabla 2). De los 72 atributos que usaron los medios independientes para el tratamiento de estos 16 eventos, 53 fueron asumidos en su dimensión sustantiva por la prensa oficial. En algunos casos esta presencia puede deberse a que constituyen elementos importantes del hecho en sí mismo, pero en muchos se aprecia que su uso se debió a la intención de responder a los medios no oficiales, como se evidencia por la mención a determinadas fuentes de origen y por el uso de valoraciones generalmente contrarias en la dimensión afectiva. En los casos en que no se dio esta dinámica de "respuesta", los medios oficiales tendieron a omitir aquellos atributos presentados por la prensa independiente que tocaban aspectos negativos del desempeño de entidades estatales.

Tabla 2

Atributos y dimensiones de los diferentes objetos en los medios no oficiales y oficiales

\begin{tabular}{|c|c|c|c|c|}
\hline \multirow[b]{2}{*}{ Evento } & \multicolumn{2}{|c|}{ Medios no oficiales } & \multicolumn{2}{|c|}{ Medios oficiales } \\
\hline & Dimensión sustantiva & $\begin{array}{l}\text { Dimensión } \\
\text { afectiva }\end{array}$ & Dimensión sustantiva & $\begin{array}{l}\text { Dimensión } \\
\text { afectiva }\end{array}$ \\
\hline \multirow{8}{*}{ Prisión Ferrer } & Arresto de Ferrer & Negativo & Arresto de Ferrer & Neutro \\
\hline & $\begin{array}{l}\text { Cumplimiento del debido } \\
\text { proceso }\end{array}$ & Negativo & $\begin{array}{l}\text { Cumplimiento del debido } \\
\text { proceso }\end{array}$ & Positivo \\
\hline & Condena internacional & Positivo & Condena internacional & Negativo \\
\hline & Tratamiento en prisión & Negativo & Tratamiento en prisión & Positivo \\
\hline & $\begin{array}{c}\text { Criminalización de la } \\
\text { oposición }\end{array}$ & Negativo & Oposición interna & Negativo \\
\hline & José Daniel Ferrer & Positivo & José Daniel Ferrer & Negativo \\
\hline & & & $\begin{array}{c}\text { Vinculación de Ferrer con } \\
\text { EE.UU. }\end{array}$ & Negativo \\
\hline & & & Actuación Gobierno EE.UU & Negativo \\
\hline \multirow{6}{*}{ Muerte de bebé } & Estado de la vacuna & Negativo & Estado de la vacuna & Positivo \\
\hline & Atención de las autoridades & Negativo & Atención de las autoridades & Positivo \\
\hline & Atención de los médicos & Positivo & Atención de los médicos & Positivo \\
\hline & Sistema de salud cubano & Negativo & Sistema de salud cubano & Positivo \\
\hline & Cobertura mediática del caso & Negativo & Importancia de la vacunación & Positivo \\
\hline & Estado de los padres & Negativo & & \\
\hline
\end{tabular}

Tabla 2 continua en la siguiente página.

Global Media Journal México, 18(34), 18-49, enero - junio 2021. 
Continuación de Tabla 2.

\begin{tabular}{|c|c|c|c|c|}
\hline \multirow{7}{*}{ Hospital Baracoa } & \multirow{7}{*}{$\begin{array}{l}\text { Disponibilidad de camas } \\
\text { Atención de los médicos } \\
\text { Estado del hospital } \\
\text { Disponibilidad de } \\
\text { medicamentos }\end{array}$} & \multirow{7}{*}{$\begin{array}{c}\text { Negativo } \\
\text { Positivo } \\
\text { Negativo } \\
\text { Negativo }\end{array}$} & \multirow{4}{*}{$\begin{array}{l}\text { Disponibilidad de camas } \\
\text { Atención de los médicos } \\
\text { Estado del hospital }\end{array}$} & \multirow{4}{*}{$\begin{array}{l}\text { Positivo } \\
\text { Positivo } \\
\text { Positivo }\end{array}$} \\
\hline & & & & \\
\hline & & & & \\
\hline & & & & \\
\hline & & & Directiva del hospital & Positivo \\
\hline & & & Impacto Bloqueo de EE.UU. & Negativo \\
\hline & & & $\begin{array}{c}\text { Actitud ante bloqueo de } \\
\text { EE.UU }\end{array}$ & Positivo \\
\hline \multirow{6}{*}{ Historiador BNC } & Frases racistas & Negativo & Frases racistas & Negativo \\
\hline & Frases homofóbicas & Negativo & Cuba ante el racismo & Positivo \\
\hline & Tv Cubana & Negativo & & \\
\hline & Racismo en BNC & Negativo & & \\
\hline & Reacciones ciudadanas & Neutro & & \\
\hline & $\begin{array}{l}\text { Actitud de conductor del } \\
\text { programa }\end{array}$ & Negativo & & \\
\hline \multirow{7}{*}{ Recogida perros } & Actuación de Zoonosis & Negativo & Actuación de Zoonosis & Positivo \\
\hline & Denuncias activistas & Neutro & Denuncias de activistas & Negativo \\
\hline & Protesta en Zoonosis & Positivo & Protesta en Zoonosis & Neutro \\
\hline & Reunión con MINSAP & Negativo & Reunión con MINSAP & Positivo \\
\hline & $\begin{array}{l}\text { Inexistencia de Ley de } \\
\text { Protección }\end{array}$ & Negativo & $\begin{array}{l}\text { Proyección hacia Ley de } \\
\text { Protección }\end{array}$ & Positivo \\
\hline & Aniversario 500 Habana & Negativo & & \\
\hline & Solidaridad de personalidades & Neutro & & \\
\hline \multirow{6}{*}{ Funcionarios Bolivia } & Detención de funcionarios & Neutro & Detención de funcionarios & Negativo \\
\hline & & Neutro & $\begin{array}{c}\text { Acusación de financiar } \\
\text { revueltas }\end{array}$ & Negativo \\
\hline & $\begin{array}{c}\text { Implicación del gobierno } \\
\text { cubano }\end{array}$ & Neutro & $\begin{array}{l}\text { Acusación Implicación } \\
\text { gobierno cubano }\end{array}$ & Negativo \\
\hline & $\begin{array}{c}\text { Acusaciones gobierno de } \\
\text { Bolivia }\end{array}$ & Neutro & $\begin{array}{c}\text { Acusaciones gobierno de } \\
\text { Bolivia }\end{array}$ & Negativo \\
\hline & & & Participación de EUA & Negativo \\
\hline & & & Colaboración médica cubana & Positivo \\
\hline \multirow{6}{*}{ Concierto Haila } & Actuación comunidad cubana & Positivo & $\begin{array}{l}\text { Actuación de parte de } \\
\text { comunidad cubana }\end{array}$ & Negativo \\
\hline & Haila María Mompié & Negativo & Haila María Mompié & Positivo \\
\hline & $\begin{array}{l}\text { Relación Haila con gobierno } \\
\text { Cuba }\end{array}$ & Negativo & $\begin{array}{l}\text { Relación Haila con gobierno } \\
\text { Cuba }\end{array}$ & Neutro \\
\hline & $\begin{array}{l}\text { Artistas con relaciones con } \\
\text { gobierno }\end{array}$ & Negativo & & \\
\hline & Intercambio cultural & Negativo & & \\
\hline & $\begin{array}{c}\text { Declaración persona non } \\
\text { grata }\end{array}$ & Neutro & & \\
\hline \multirow{6}{*}{ Apertura mercado } & $\begin{array}{c}\text { Comportamiento de los } \\
\text { usuarios }\end{array}$ & Neutro & $\begin{array}{c}\text { Comportamiento de los } \\
\text { usuarios }\end{array}$ & Negativo \\
\hline & Abastecimiento en la capital & Negativo & Abastecimiento en la capital & Positivo \\
\hline & Reparación del inmueble & Positivo & Reparación del inmueble & Positivo \\
\hline & Actuación policía & Neutro & Actuación policía & Positivo \\
\hline & $\begin{array}{l}\text { Preparación de la } \\
\text { administración }\end{array}$ & Negativo & $\begin{array}{l}\text { Preparación de la } \\
\text { administración }\end{array}$ & Negativo \\
\hline & & & Réplicas en las redes sociales & Negativo \\
\hline
\end{tabular}

Global Media Journal México, 18(34), 18-49, enero - junio 2021. 
Continuación de Tabla 2.

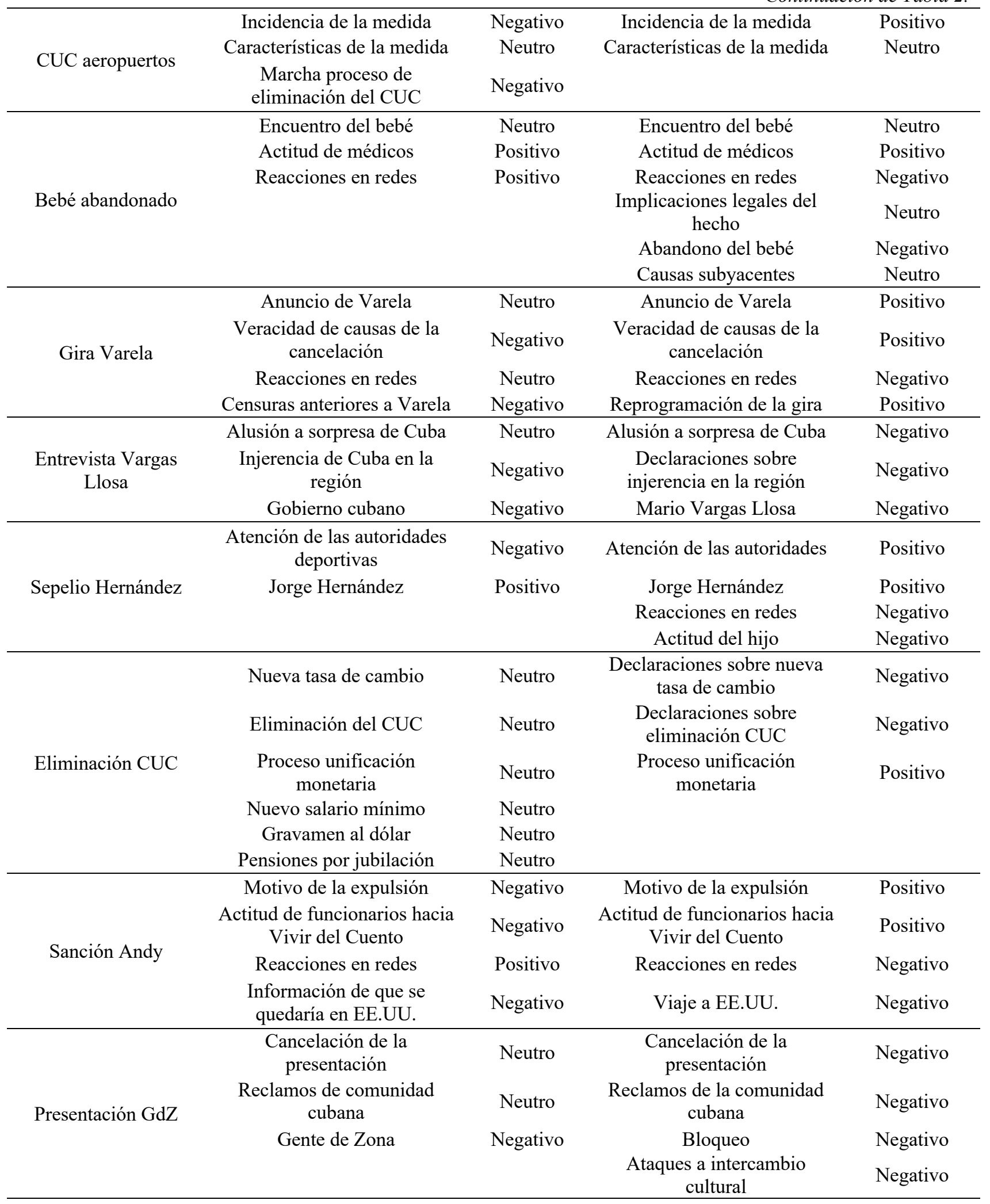

Global Media Journal México, 18(34), 18-49, enero - junio 2021. 
Esta diferencia en la dimensión afectiva de los atributos es concordante con la ausencia de transferencia de encuadres encontrada. Como se explicará más adelante, el reencuadre fue una de las estrategias empleadas por los medios oficiales para abordar los eventos tratados previamente en la prensa independiente.

\section{Estrategias de tratamiento periodístico}

El análisis del tratamiento dado por los medios oficiales a temas visibilizados previamente por la prensa no oficial permitió distinguir una serie de estrategias que matizan este proceso de intermedia agenda setting. Estas son:

\section{a) No mención a medios no oficiales}

Una de las máximas de la comunicación de campañas electorales es no mencionar al adversario, para no darle visibilidad. Al parecer, esta es una práctica asumida por quienes dirigen la política editorial e informativa de los medios oficiales cubanos.

Como puede verse en la Tabla 3, la opción más recurrente dentro de los diferentes textos analizados de los medios oficiales fue responder a “criterios", "preocupaciones", “campañas", “comentarios" provenientes de las redes sociales. De los ocho temas en los que mencionaron a las redes, solo la mitad tuvo ese origen. La otra mitad (prisión de Ferrer, detención de funcionarios, eliminación del
CUC en aeropuertos y sanción a Andy Vázquez) fueron difundidos primero o mayormente en medios no oficiales y replicados en las redes. Sin embargo, la prensa oficial no hizo alusión a estos.

Otra de las prácticas fue atribuir el origen a otras referencias, generalmente ambiguas y planteadas de forma despectiva. Por ejemplo "una nube de tiñosas", "rapiñeros", “opinadores digitales", "manipulaciones", "rumores" y "un sector del exilio cubano en Estados Unidos”.

También fue recurrente tratar el hecho sin hacer referencia a las fuentes donde apareció originalmente y en menor medida mencionar a un gobierno extranjero, fundamentalmente al de Estados Unidos, como el generador o impulsor del hecho noticioso.

Sin embargo, llama la atención que nunca mencionaron a los medios independientes cubanos de manera general, ni haciendo mención a alguno en específico de manera concreta, a pesar de que en ciertos casos era evidente la referencia a encuadres y atributos provenientes de estos medios.

El evento de la eliminación del CUC es muy ilustrativo, ya que las respuestas oficiales aludieron directamente a la tasa de cambio de 1x50 mencionada en una supuesta filtración publicada por el medio independiente CiberCuba (Cabrera, 2019). Sin embargo, los medios oficiales refirieron que el ministro de Economía desmintió "versiones de prensa" (Cubadebate, 2019). 


\section{Tabla 3}

Fuentes de procedencia de la noticia mencionadas por los medios oficiales

\begin{tabular}{|c|c|c|}
\hline Fuentes mencionadas & Evento & $\begin{array}{c}\text { Cantidad de trabajos } \\
\text { periodísticos }\end{array}$ \\
\hline \multirow{2}{*}{ Medio específico } & Entrevista Vargas Llosa & 2 \\
\hline & Presentación GdZ & 1 \\
\hline \multicolumn{3}{|c|}{ Medios cubanos no oficiales (en general) } \\
\hline \multirow{2}{*}{ Medios (en general) } & Prisión Ferrer & 2 \\
\hline & Eliminación CUC & 2 \\
\hline \multirow{8}{*}{ Redes sociales } & Prisión Ferrer & 1 \\
\hline & Recogida perros & 4 \\
\hline & Detenidos Bolivia & 1 \\
\hline & Apertura mercado & 3 \\
\hline & CUC aeropuertos & 1 \\
\hline & Bebé abandonado & 1 \\
\hline & Sepelio Hernández & 1 \\
\hline & Sanción Andy & 1 \\
\hline \multirow{3}{*}{ Gobiernos extranjeros } & Prisión Ferrer & 3 \\
\hline & Detenidos Bolivia & 1 \\
\hline & Presentación GdZ & 1 \\
\hline \multirow{6}{*}{ Otros } & Muerte bebé & 1 \\
\hline & Concierto Haila & 1 \\
\hline & Gira Varela & 1 \\
\hline & Entrevista Vargas Llosa & 1 \\
\hline & Eliminación CUC & 2 \\
\hline & Sanción Andy & 1 \\
\hline \multirow{6}{*}{ No mención } & Muerte bebé & 2 \\
\hline & Hospital Baracoa & 1 \\
\hline & Historiador BNC & 1 \\
\hline & Detenidos Bolivia & 2 \\
\hline & Sanción Andy & 1 \\
\hline & Presentación GdZ & 1 \\
\hline
\end{tabular}

Igual ocurrió en el texto publicado por el medio oficial Cubadebate sobre la muerte de una bebé por vacunación (Doimeadios y Carmona, 2019). En este no se hizo mención a los medios independientes, sin embargo, se trató de desmentir cuestiones mencionadas por estos, relacionadas con las denuncias de la madre por mala atención de funcionarios de Salud Pública.

La única referencia cercana a un medio de comunicación no oficial fue hecha en un texto de Cubasí sobre la cancelación de la presentación del dúo musical Gente de Zona en un concierto en Miami (Lagarde, 2019). En alusión al presentador del show 
Hola Otaola, el autor del texto se refirió a "la campaña contra los artistas cubanos desatada en las redes sociales por los epígonos de los Pérez Roura y Ninoska Pérez, ahora disfrazados de payasos en Youtube”. Pero no mencionó ni su nombre, ni el del programa.

Por otra parte, fue encontrado un caso en que dos veces hicieron referencia de manera indirecta al medio norteamericano Radio TV Martí: "un canal de la televisión de Estados Unidos, diseñado especialmente para Cuba con fines subversivos" (UNEAC, 2019), "la televisión de Miami” (Concepción, 2019).

\section{b) Tiempos de respuesta}

Una de las cuestiones que más se ha criticado a la prensa cubana oficial es su lentitud (García Luis, 2004) para abordar los sucesos de la realidad o para "responder" a cuestiones relacionadas con el país procedentes de medios internacionales, nacionales no oficiales o las redes.

Como se aprecia en la Tabla 4, pudieron identificarse cuatro tipos de ciclo de respuesta. Algunas noticias fueron abordadas al día siguiente de haber sido dadas a conocer por los medios independientes y las redes sociales. A esto puede llamársele un ciclo corto.

El ciclo medio, es aquel en que la respuesta o tratamiento al tema ocurrió dentro de la semana en que se produjo el suceso. Puede observarse como el margen temporal más reiterado en este caso fue de cuatro días. Para la inmediatez con que circula la información en la actualidad, incluso en Cuba, son lapsos demorados.
Aquellos sucesos cubiertos entre una semana y dos posteriores a la aparición de la noticia, se consideraron ciclos largos. Por último, son ciclos extra largos cuando el tema es abordado después de dos semanas de su ocurrencia.

Aunque esta investigación no incluyó entrevistas $u$ observaciones que permitieran determinar la ubicación de cada noticia en los diferentes ciclos, pueden arribarse a algunas conclusiones a partir de características estructurales de los medios oficiales cubanos.

La explicación de fondo en todos los casos está en la falta de autonomía de la prensa oficial cubana, que como señaló García Luis (2004) no constituye un sistema independiente, sino que es parte del sistema político. De ahí que la velocidad de respuesta que debe caracterizar a un medio de comunicación se ve afectada por la necesidad de autorización proveniente de un agente externo (Partido-Gobierno) y los plazos temporales que implica recorrer los diferentes niveles de jerarquía de estas estructuras, en un contexto altamente verticalizado donde un error puede tener altos costos políticos y administrativos.

La presencia de algunas noticias en el ciclo corto (funcionarios detenidos en Bolivia, sepelio de Jorge Hernández) y medio (entrevista a Vargas Llosa) dependió de la agilidad con que los organismos gubernamentales correspondientes respondieron a las mismas. La prensa no funcionó aquí como un sistema que reacciona generando información ante la ocurrencia de un suceso, sino que sirvió como vocera de agentes externos. En el caso de los funcionarios detenidos, una vez que la prensa 
oficial recibió el banderazo de salida, continuó informando o editorializando durante varios días.

En el caso de la apertura del mercado Cuatro Caminos es llamativo que a pocas horas de ocurridos los desórdenes que provocaron daños a la instalación, algunos periodistas de los medios oficiales emitieron a título personal opiniones en sus redes sociales. Sin embargo, no fue hasta el día siguiente - $-\mathrm{y}$ producto de las inquietudes que motivó una escueta nota institucional publicada anunciando el cierre temporal del mercado- que fueron abordados en los medios oficiales los hechos que ya estaban en muchos de los medios independientes y viralizados en redes sociales.

En el caso de los hechos que fueron abordados en ciclos medios y largos, se mezclan la lentitud operativa de los medios oficiales cubanos, los permisos para abordar ciertos temas y la presión que genera la propia evolución de los acontecimientos que se pretende ocultar. Por ejemplo, el Ministerio de Salud Pública no se pronunció sobre la muerte de la bebé por vacunación (Redacción Digital, 2019) hasta que luego de varios días siguió creciendo el clima de indignación y temor a través de las redes sociales.

\section{Tabla 4}

Lapso temporal transcurrido entre la aparición de los eventos en los medios no oficiales y su publicación en la prensa oficial

\begin{tabular}{|c|c|c|c|c|}
\hline Evento & $\begin{array}{c}\text { Publicación en } \\
\text { medios no oficiales }\end{array}$ & $\begin{array}{l}\text { Publicación en } \\
\text { medios oficiales }\end{array}$ & $\begin{array}{l}\text { Tiempo de } \\
\text { respuesta }\end{array}$ & Tipo de ciclo \\
\hline Prisión Ferrer & 1ro de octubre & 19 de noviembre & 49 días & \multirow{3}{*}{ Extra largo } \\
\hline Historiador Ballet & 30 de octubre & 20 de noviembre & 21 días & \\
\hline Gira Varela & 29 de noviembre & 18 de diciembre & 19 días & \\
\hline Concierto Haila & 12 de noviembre & 20 de noviembre & 8 días & \multirow{2}{*}{ Largo } \\
\hline Sanción Andy & 19 de diciembre & 26 de diciembre & 7 días & \\
\hline Entrevista Vargas Llosa & 5 de diciembre & 10 de diciembre & 5 días & \multirow{8}{*}{ Medio } \\
\hline Muerte bebé & 8 de octubre & 12 de octubre & 4 días & \\
\hline Recogida perros & 8 de noviembre & 12 de noviembre & 4 días & \\
\hline Bebé abandonado & 25 de noviembre & 29 de noviembre & 4 días & \\
\hline Eliminación CUC & 18 de diciembre & 21 de diciembre & 4 días & \\
\hline Presentación GdZ & 23 de diciembre & 27 de diciembre & 4 días & \\
\hline CUC aeropuertos & 20 de noviembre & 23 de noviembre & 3 días & \\
\hline Hospital Baracoa & 29 de octubre & 31 de octubre & 2 días & \\
\hline Detenidos Bolivia & 14 de noviembre & 15 de noviembre & 1 día & \multirow{3}{*}{ Corto } \\
\hline Apertura mercado & 16 de noviembre & 17 de noviembre & 1 día & \\
\hline Sepelio Hernández & 16 de diciembre & 17 de diciembre & 1 día & \\
\hline
\end{tabular}

Global Media Journal México, 18(34), 18-49, enero - junio 2021. 
Algo similar ocurrió con la recogida y sacrificio de perros, que no fue mencionada hasta que un grupo de animalistas protagonizó una protesta frente a la sede de Zoonosis (Razones de Cuba, 2019a).

Pudiera pensarse que la demora se deba a la realización de investigaciones más profundas, pero no parece ser el caso. El texto sobre el bebé abandonado publicado en el medio oficial Juventud Rebelde (Peña, 2019) cuatro días después de ocurrido el hecho, no aportó ningún elemento informativo diferente a los que mencionaron los medios no oficiales desde el primer momento.

En cuanto a los hechos que fueron tratados dentro de ciclos extra largos, hay dos elementos resaltables. La detención y encarcelamiento de Ferrer fue un tema que el gobierno evitó abordar, a pesar de ser una noticia que resonó muchísimo durante más de un mes en redes sociales, medios independientes, prensa internacional y circuitos diplomáticos. Sin embargo, hasta que el tema no escaló dentro de la agenda política de la Unión Europea, la prensa oficial no lo abordó. Fue una decisión política, no mediática. Después de casi dos meses de silencio, el caso de Ferrer fue motivo de una campaña negativa durante varios días en toda la prensa oficial. Este es un ejemplo de que algunos de los temas abordados en ciclos extra largos, se ubican dentro de los llamados temas tabú de la prensa cubana, y que son tratados porque la acumulación crítica de presiones externas obliga a hacerlo.

El caso de las declaraciones del Historiador del BNC también muestra otra de las causas por las que un tema es tratado varias semanas después de su ocurrencia e incluso, cuando ya ha salido de las agendas públicas y de los medios alternativos. El hecho fue mencionado tangencialmente en un texto de Granma sobre el racismo (De la Hoz, 2019), el día antes de que el Consejo de Ministros anunciara la creación de un Programa Nacional contra el racismo y la discriminación racial. Esta es una de las taras no escritas del periodismo oficial cubano: no tratar los problemas hasta que no se tenga una "solución", una concepción lamentablemente afianzada en algunos discursos gremiales, políticos y hasta académicos sobre el papel del periodismo en Cuba.

\section{c) Extensión del tratamiento}

Las variaciones en este aspecto es otra de las estrategias de los medios oficiales para tratar o dar respuesta a temas que son puestos en la agenda por los medios no oficiales. Siete temas fueron abordados de manera puntual (Declaraciones del historiador del BNC, Concierto de Haila, Bebé abandonado, Hospital de Baracoa, Gira de Varela, Eliminación de CUC en aeropuertos y Sepelio de Jorge Hernández) con un solo trabajo periodístico o nota institucional, que en algunos casos fueron reproducidos simultáneamente en varios medios.

Por su parte, a los temas restantes se les dedicaron varios trabajos en medios diferentes. En casos como el encarcelamiento de Ferrer, la apertura del mercado de Cuatro Caminos, la recogida de perros, los funcionarios detenidos en Bolivia, puede hablarse de la existencia de campañas alrededor del tema, con varios textos en diferentes medios y formatos, concentrados temporalmente. No obstante, los casos de Ferrer y Cuatro Caminos, también tuvieron reapariciones posteriores. 
La muerte de la bebé por vacunación, la eliminación del CUC, la entrevista de Vargas Llosa y la sanción al actor Andy Vázquez, fueron hechos tratados en varias ocasiones, a partir de trabajos con cierta distancia temporal respecto a la primera referencia al hecho en medios oficiales. Generalmente fueron textos opináticos $\mathrm{y}$ de profundización que volvían sobre el hecho en cuestión. La suspensión del concierto de Gente de Zona fue abordada por dos trabajos diferentes aparecidos el mismo día.

\section{d) Tratamiento tangencial}

En dos casos pudo apreciarse que los medios optaron por un tratamiento tangencial, evitando hacer referencia al hecho concreto que había provocado los estados de opinión. Así sucedió con el trabajo publicado en Cubadebate sobre el hospital del municipio de Baracoa (Valdés, 2019). Dos días antes los medios independientes habían reportado la denuncia en redes sociales de una madre sobre la situación de hacinamiento y escasez de medicamentos en esa instalación de salud del oriente cubano. Sin hacer referencia a este hecho o a la situación que lo generó, Cubadebate publicó un texto sobre ese hospital en el cual su director mencionó que tenían cobertura de camas y que, a pesar de las carencias provocadas por el bloqueo de Estados Unidos, no han dejado de funcionar y brindar un buen servicio. El artículo fue realizado por una periodista que confiesa no haber tenido "la oportunidad de ir todavía a Baracoa" y que las entrevistas las realizó online.
También resulta ilustrativo que, en medio del rumor de la expulsión de Andy Vázquez, Cubadebate publicó el 26 de diciembre un texto donde anunciaba el estreno de nuevos capítulos (Armas, 2019), pero sin tocar el tema de la sanción de Vázquez y usando una foto en la que aparecía este actor junto al resto del elenco, a pesar de que cuatro días después emitirían el primer capítulo de la nueva temporada del programa donde confirmaban su salida definitiva. Este tipo de acciones en los medios suelen emplearse en contextos de incertidumbre para intentar aplacar la opinión pública sobre un tema en específico y minar la credibilidad de quienes han realizado pronunciamientos al respecto. La ausencia del actor en el programa el 30 de diciembre hizo que varios días después el tema tuviera que ser abordado directamente en medios oficiales, aunque con muy poca precisión.

\section{e) Doble agenda}

La política informativa centralizada de los medios oficiales cubanos trae consigo una homogeneidad de las diferentes agendas de estos (Gallego, 2016). Por otra parte, la totalidad de los medios oficiales cubanos nacionales ya tienen presencia en la web y publican allí los textos y trabajos que presentan en sus soportes tradicionales.

Sin embargo, cuatro de los temas abordados primero por los medios independientes solo fueron tratados por la prensa oficial desde medios netamente digitales. Fueron los casos del hacinamiento en el hospital de Baracoa, el sepelio de Jorge Hernández, la sanción al actor Andy Vázquez y la cancelación de la presentación del dúo musical Gente de Zona.

Global Media Journal México, 18(34), 18-49, enero - junio 2021. 
Estos fueron temas que pasaron desapercibidos o solo llegaron en forma de rumores para esa gran parte de la población cubana que aún no accede a Internet y que depende de los medios tradicionales (todos en manos del Estado) para informarse.

Pero no solo pudo apreciarse diferencia entre las agendas de los medios tradicionales y digitales en cuanto a temas, sino también en cuanto a elementos específicos de los hechos. Por ejemplo, en el caso de la recogida de perros, la manifestación realizada por protectores frente a Zoonosis y la reunión que posteriormente sostuvieron con funcionarios del Ministerio de Salud Pública, solo fueron mencionadas en uno de los medios digitales que tocó el tema (Razones de Cuba, 2019); no así en los trabajos aparecidos sobre esta cuestión en la televisión y la prensa impresa.

Otra variación llamativa estuvo relacionada con la forma de mencionar la fuente de la noticia en el caso de la eliminación del CUC. El Granma en su versión de la web, al igual que otros medios oficiales en formato digital (Cubadebate, 2019), hizo alusión a "versiones de prensa", mientras que en su edición impresa esta frase fue sustituida por "ciertas manipulaciones" (Redacción Nacional, 2019).

Así mismo, la alusión al presentador del show Hola Otaola, única en toda la muestra en que se hace referencia a un espacio de comunicación cubano no oficial, ocurrió en un texto que solo circuló en formato digital. Existe una intención de no promover estos medios que circulan en el ciberespacio entre los amplios públicos cubanos sin acceso a Internet.

\section{f) Reencuadre}

Esta es una de las estrategias más evidentes y repetitivas del tratamiento dado por los medios oficiales a las noticias provenientes de las agendas de la prensa independiente. Como puede observarse en la Tabla 5, las diferencias en la definición de los problemas son muy notables. En algunos casos implican la contradicción total (recogida y sacrificio de perros, eliminación del CUC), en otros dirigen la atención hacia aspectos diferentes del problema (encarcelamiento de Ferrer, funcionarios detenidos en Bolivia, concierto de Haila, bebé abandonado). También recurren al uso de palabras con cargas semánticas diferentes (muerte de bebé por vacunación, apertura mercado de Cuatro Caminos, gira de Varela, presentación de Gente de Zona) y la justificación/minimización del problema magnificando la incidencia de otra situación (declaraciones historiador del BNC y condiciones del hospital de Baracoa).

Estas diferencias son también muy evidentes en los diagnósticos de las causas. El único caso en que hubo coincidencia fue en el del bebé abandonado, que tanto oficiales como no oficiales señalaron que se desconocían las causas. En el tratamiento al concierto de Haila, la apertura del mercado Cuatro Caminos, la gira de Varela y la eliminación del CUC en los aeropuertos tuvieron algunas coincidencias, aunque con matices importantes. 
Tabla 5

Encuadres empleados en medios no oficiales y medios oficiales

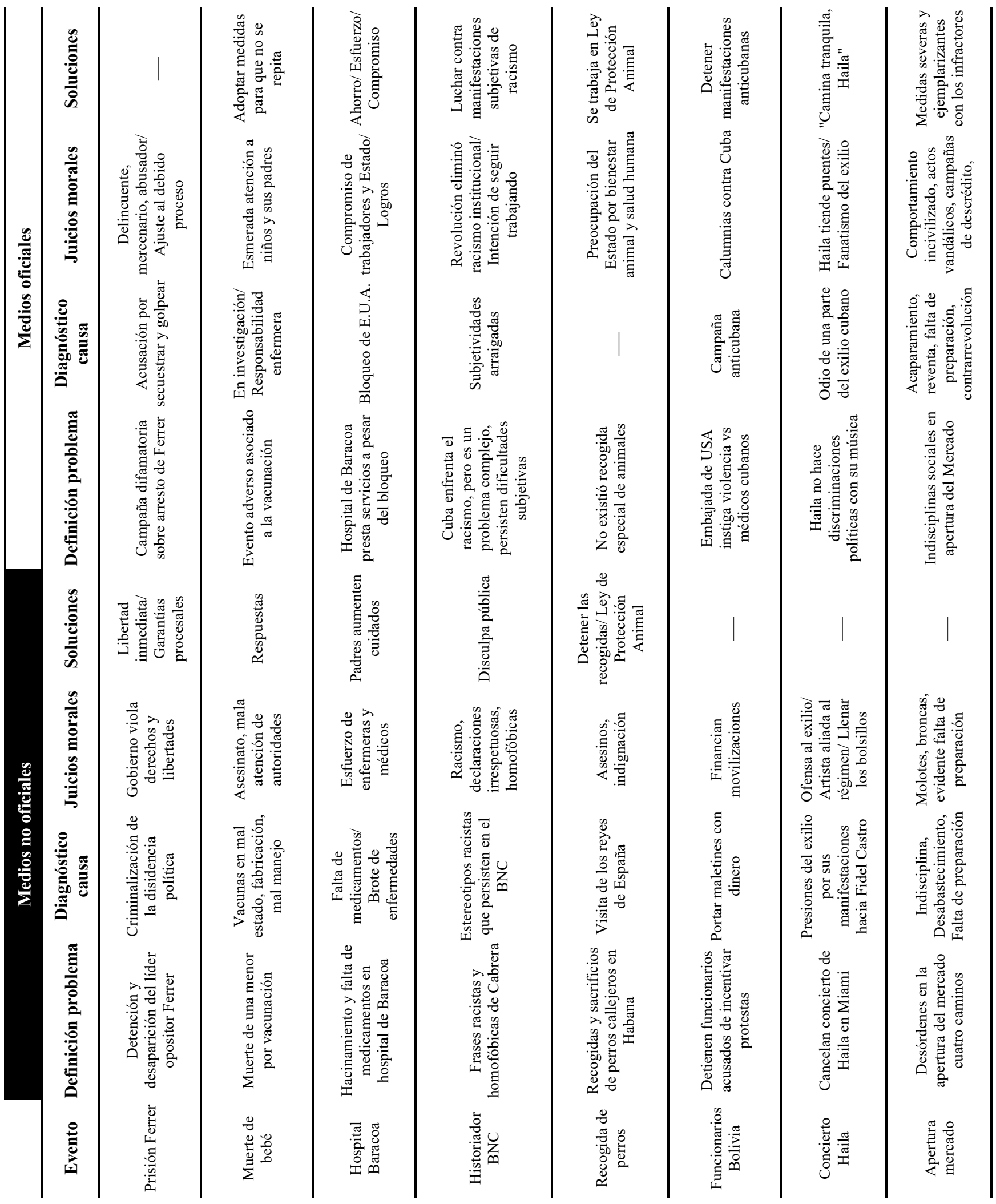


Tabla 5 (... continuación)

Encuadres empleados en medios no oficiales y medios oficiales

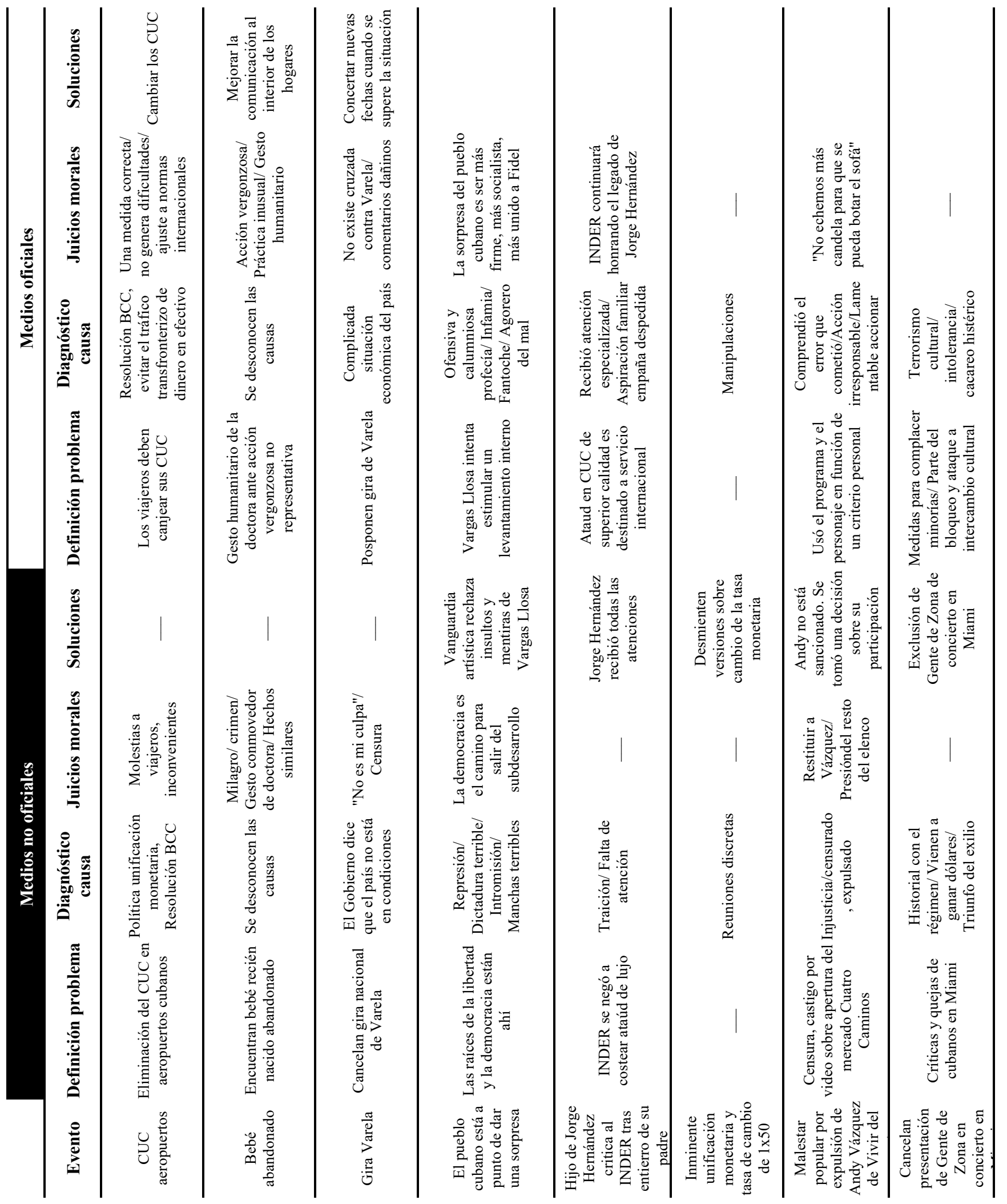


Esta polarización también puede verse de manera muy clara en los juicios morales, generalmente con fuertes cargas afectivas en ambos tipos de medios. En cuanto a los encuadres de soluciones, también las diferencias son notables. En los medios no oficiales van enfocados mayormente a exigencias al Gobierno cubano, mientras que en la prensa oficial las soluciones concebidas, en todos los casos, pueden clasificarse como optimistas, conciliadoras, y de defensa/apoyo de las políticas estatales.

En este último aspecto llama la atención que en la mayoría de los casos el tratamiento de los medios oficiales incluyó este tipo de encuadre, a diferencia de la prensa independiente. Ello es consistente con el papel "orientador" — supeditado a los objetivos del poder político- que se remarca a los medios de comunicación cubanos y el rol lealfacilitador que prima en las culturas profesionales de los periodistas de medios oficiales (Olivera y Torres, 2017).

El reencuadre, como estrategia de tratamiento a los temas visibilizados por los medios no oficiales, incluyó en varios casos la omisión de algunos atributos del evento que implicaban connotaciones negativas para el Gobierno o entidades estatales.

Debe llamarse la atención respecto al hecho de que, independientemente de la naturaleza del tema en cuestión, tanto en los medios oficiales como en los no oficiales, los encuadres empleados contenían marcadas connotaciones políticas.

\section{Conclusiones}

El monitoreo realizado durante tres meses a medios no oficiales y oficiales permite sostener que existió efecto de intermedia agenda setting. Por una parte, los plazos temporales evidencian que la aparición de algunos de estos temas en la agenda de los medios oficiales se debió a la existencia de transferencia de eventos, que también se dio a nivel de atributos en su dimensión sustantiva.

En total, fueron 16 los temas tratados en la prensa independiente que luego aparecieron en los medios oficiales. Fueron hechos concretos que clasifican como eventos. Se distribuyeron en ocho objetos, algunos de ellos con presencia sistemática en los medios oficiales cubanos, aunque con atributos diferentes.

No obstante, en algunos de los casos no puede definirse con suficiente claridad si la aparición de estos temas en la agenda de los medios oficiales se debió a procesos de transferencia de relevancia, o si es producto de un efecto de retardo provocado por la lentitud que genera la falta de autonomía de la prensa oficial.

Al tratarse de transferencia de relevancia desde medios alternativos hacia una prensa oficial que resulta hegemónica en el contexto cubano, se está en presencia de un caso en que los primeros funcionan como inter-media agenda initiator (Song, 2007). Aunque esta investigación no aplicó técnicas que permitieran arribar a explicaciones causales para este aspecto, la posición de rechazo manifiesto por parte de la prensa oficial hacia los medios

Global Media Journal México, 18(34), 18-49, enero - junio 2021. 
independientes, sugiere que la transferencia de relevancia en la mayoría de los casos no se debió a luchas por la primicia, a la influencia de referentes y ni siquiera, a la influencia de expectativas mutuas, como suele suceder en los estudios de este corte realizados en sistemas liberales (Gans, 2004).

Por el contrario, pudiera decirse que fue la posición de enfrentamiento con un sistema concebido como opuesto - y que en la actualidad le disputa la hegemonía informativa y de construcción de sentidos en sectores de público específicos- lo que provocó la inclusión o respuesta a determinados eventos que adquirieron relevancia, ya sea por la atención que le prestó el público o por el peso político que poseían.

Esta tesis del enfrentamiento ideológico como principal acicate del efecto de transferencia, se ve respaldada por la marcada diferencia y oposición de los encuadres que presentaban los medios oficiales con respecto a los resaltados por medios independientes, así como por el destaque en todos los temas, sin excepción, de aspectos políticos.

Se identificaron seis estrategias empleadas por los medios oficiales a la hora de asumir los temas previamente abordados en los medios independientes. La primera de ellas fue no mencionar a los medios no oficiales ni de manera general, ni de forma concreta, aun cuando algunos trabajos dialogaban de manera inequívoca con textos específicos publicados por medios independientes. Esta reticencia, manifiesta y avala la tesis de que el efecto de intermedia agenda setting fue resultado más de lógicas de oposición que de reconocimiento o colaboración.
Se encontraron diferentes tiempos de respuesta, los cuales pudieran estar condicionados por la falta de autonomía de los medios oficiales respecto a temas de cierta complejidad, así como por el nivel de agilidad de los organismos gubernamentales de donde emergían los permisos o las respuestas a los temas puestos en la agenda por los medios independientes y las redes sociales.

Algunos temas fueron abordados en un solo trabajo periodístico mientras que a otros les dedicaron varios. Pudo apreciarse que algunos hechos fueron tratados tangencialmente, sin hacer referencia a la situación concreta que los originó, mientras que otros fueron abordados solamente en medios en formato digital, manteniéndose alejados de los medios tradicionales y los grandes sectores de público que solo tienen acceso a estos. Esta doble agenda no solo se evidenció a nivel temático, sino también a nivel de atributos.

Otra de las estrategias más evidentes y persistentes fue el reencuadre de los temas presentados en los medios no oficiales, ya sea redefiniendo el problema, los diagnósticos de causas, los juicios morales o las soluciones.

Se sugiere que próximos estudios que vuelvan sobre este tema empleen técnicas como la observación y la entrevista que permitan ofrecer respuestas más precisas sobre los factores que intervienen en la transferencia de relevancia desde los medios independientes hacia los oficiales y determinan las estrategias de tratamiento. También es recomendable realizar investigaciones con marcos temporales más amplios que permitan observar si existe transferencia a nivel de objetos. 
Que se haya encontrado evidencia de la existencia del efecto de intermedia agenda setting no quiere decir que la prensa independiente fije la agenda de los medios oficiales, lo cual es muy poco probable cuando se trata de una relación desproporcionada entre medios alternativos y hegemónicos, favorable a estos últimos.

Sin embargo, la prensa independiente, a pesar de sus dificultades logísticas, por lo general reacciona con más rapidez ante los estímulos de la realidad debido a su autonomía y también, posee una política informativa más cercana a temas de preocupación pública que constituyen vacíos en los medios oficiales. Ello provoca que le lleve la delantera a la prensa oficial en noticias que rápidamente atraen segmentos importantes de la atención pública o tienen impacto a nivel de política extra fronteras, lo cual hace que en algunos casos los medios oficiales tengan que prestarle atención tardíamente para realizar control de daños.

El hecho de que los medios independientes cubanos logren poner determinados sucesos en la agenda de la prensa oficial es un indicador importante de la relevancia de su trabajo y del terreno que han ido conquistando en tanto actores con cierta capacidad de incidencia sobre las agendas públicas y también sobre las agendas políticas que controlan las agendas mediáticas oficiales. En momentos de alta complejidad en el escenario político y social cubano, esta es una cuestión para significar.

\section{Referencias bibliográficas}

Acosta, O. (21 de noviembre de 2019). Haila, ¿preparen, apunten, fuego? Granma. 6. https://bit.ly/3iqlNAT

Alonso, L. M. (23 de noviembre de 2019). Sobre el cambio de moneda en los aeropuertos cubanos. NTV. https://bit.ly/3pxa0SK

Armas, P. (26 de diciembre de 2019). "Vivir del cuento" de estreno el lunes 30 de diciembre. Cubadebate. https://bit.ly/3gmtoxt

Armas, P. (3 de enero de 2020). Facundo, «Vivir del cuento», la censura, Silva y sigue la polémica. Cubadebate. https://bit.ly/3czMi29

Atwater, T., Fico, F., y Pizante, G. (1987). Reporting on the State Legislature: A Case Study of Inter-media Agenda Setting. Newspaper Research Journal, 8(2), 53-61. https://doi.org/10.1177/073953298700800206

Billard, T. J. (2019). Setting the transgender agenda: intermedia agenda-setting in the digital news environment. Politics, Groups, and Identities, 7(1), 165-176. https://doi.org/10.1080/21565503.2018.1532302

Cabrera, C. (18 de diciembre de 2019). Cuba fijará una tasa de cambio de 50 pesos por 1 dólar y nuevo salario mínimo. CiberCuba. https://bit.ly/2RzLaFg

Comité Ejecutivo del Consejo de Ministros. (2018). Política de Comunicación Social del Estado y el Gobierno cubanos. https://bit.ly/3g2wMyI

Concepción, E. (15 de diciembre de 2019). Una "sorpresa” para Vargas Llosa. Granma. https://bit.ly/3waVv9K

Global Media Journal México, 18(34), 18-49, enero - junio 2021. 
Conway, B. A., Filer, C. R., Kenski, K., y Tsetsi, E. (2017). Reassessing Twitter's Agenda-Building Power: An Analysis of Intermedia Agenda-Setting Effects During the 2016 Presidential Primary Season. Social Science Computer Review, XX(X), 1-15. https://doi.org/10.1177/0894439317715430

Cubadebate. (21 de diciembre de 2019). Ministro de Economía desmiente versiones sobre cambio de la tasa monetaria. Cubadebate. https://bit.ly/38MwGXU

De la Hoz, P. (20 de noviembre de 2019). El socialismo tiene que ser antirracista. Granma. https://bit.ly/3vrtZVv Denham, B. E. (2014). Intermedia Attribute Agenda Setting in the New York Times: The Case of Animal Abuse in U.S. Horse Racing. Journalism y Mass Communication Quarterly, 91(1), 17-37. https://doi.org/10.1177/1077699013514415

Denham, B. E. (2019). Coverage of the Russian Doping Scandal in the New York Times. Intramedia and Intermedia Attribute Agenda-Setting Effects. Communication y Sports, 7(3), 337-360. https://doi.org/10.1177/2167479518765188

Doimeadios, D., y Carmona, E. (16 de octubre de 2019). Evento asociado a la inmunización con PRS en Cuba: Las vacunas no son el problema. Cubadebate. https://bit.ly/3507WJt

Doucette, S. K. (2013). Mightier than the Sword: Polish Independent Publishing, 1976-1989. [tesis doctoral, Georgetown University]. Repositorio institucional. https://bit.ly/3pxGoEV

Entman, R. M. (2007). Framing Bias: Media in the Distribution of Power. Journal of Communication, 57(1), 163173. https://doi.org/10.1111/j.1460-2466.2006.00336.x

Freedom House. (2021). Cuba. Freedom on the Net 2020. Freedom House. https://bit.ly/3wYVDt0

Gallego, J. R. (2016). Medios, gobierno y ciudadanía en Cuba: Agendas, encrucijadas y realidades. Cuba Posible, (38), 81-90. https://bit.ly/34YoUbc

Gallego, J. R., y Rosabal, A. (2013). Las cartas sobre la mesa. Un estudio sobre la relación entre agenda pública y mediática en Cuba: caso Granma. Signo y Pensamiento XXXII, (62), 98-113. https://doi.org/10.11144/Javeriana.syp32-62.csme

Gans, H. J. (2004). Deciding What's News. A Study of CBS Evening News, NBC Nightly News, Newsweek, and Time. Northwestern University Press.

Garcés, R. (14 de julio de 2013). Siete tesis sobre la prensa cubana. Cubadebate. https://bit.ly/3g2OH81

García Luis, J. (2004). La regulación de la prensa en Cuba. Referentes morales y deontológicos [tesis doctoral, Universidad de La Habana]. https://bit.ly/3w7CHrQ

García Santamaría, S. (2018). The Sovietization of Cuban Journalism. The Impact of Foreign Economy Dependency on Media Structures in a Post-Soviet Era. Journal of Latin American Communication Research, 6(1-2), 135-152. https://bit.ly/3zbGUge

INDER. (17 de noviembre de 2019). Honraremos a Jorgito cada vez que suene el gong. Jit. https://bit.ly/3iqERie

Global Media Journal México, 18(34), 18-49, enero - junio 2021. 
Kai, N. Y. (2010). The relationship between blogs and newspapers in Singapore: An intermedia agenda-setting study. [tesis de maestría, National University of Singapore]. Repositorio Institucional. https://scholarbank.nus.edu.sg/handle/10635/18812

Lagarde, M. H. (27 de noviembre de 2019). Gente de Zona, el bloqueo y el cacareo histérico de Miami. Cubasí. https://bit.ly/3x70JDr

Martínez, L. (22 de noviembre de 2019). Díaz-Canel en el Consejo de Ministros: «No vamos a renunciar a las conquistas y los sueños por realizar». Granma. 2-3. https://bit.ly/3w0E7o5

Mathes, R., y Pfetsch, B. (1991). The Role of the Alternative Press in the Agenda-Building Process: Spill-over Effects and Media Opinion Leadership. European Journal of Communication, 6(1), 33-62. https://doi.org/10.1177/0267323191006001003

McCombs, M. (2014). Setting the Agenda. The Mass Media and Public Opinion (2nd ed.). Polity Press. https://bit.ly/2T9E9vs

Meraz, S. (2011). Using Time Series Analysis to Measure Intermedia Agenda-Setting Influence in Traditional Media and Political Blog Networks. Journalism y Mass Communication Quarterly, 88(1), 176-194. https://doi.org/10.1177/107769901108800110

Miller, R. E. (1991). An Investigation of Inter-Media Agenda Setting of the Drugs-In-Professional-Sports Issue. [tesis doctoral, University of Texas at Austin]. https://bit.ly/3pzThhx

MINSAP. (9 de noviembre de 2019). Información del Ministerio de Salud Pública sobre los resultados de la investigación de sucesos asociados al proceso de vacunación con PRS en La Habana del Este. Granma. 8. https://bit.ly/3ctKTLd

Muñiz, V., y Castillo, Y. (2017). La brecha entre medios y públicos en Cuba. Pautas para un diálogo necesario desde la agenda setting. Alcance. Revista Cubana de Información y Comunicación, 6(13), 87-111. https://bit.ly/34Yk1Pz

Neuman, W. R., Guggenheim, L., Jang, S. M., y Bae, S. Y. (2014). The Dynamics of Public Attention: AgendaSetting Theory Meets Big Data. Journal of Communication, 64(2), 193-214. https://doi.org/10.1111/jcom.12088

Olivera, D., y Torres, L. (2017). Análisis del periodismo en Cuba: el predominio del rol profesional leal-facilitador de los periodistas en el contenido de las noticias de prensa. En M. Oller (Ed.), Cultura(s) Periodística(s) Iberoamericana(s). La diversidad de un periodismo propio (pp. 135-161). Sociedad Latina de Comunicación Social. https://bit.ly/3gkmkSb

Padilla, A., Ramírez, E. B., y Corcho, D. (2017). Comunicación pública y democracia en Cuba: Las controversias entre medios estatales y alternativos. En A. Cabral, C. Bolaño, D. Araujo, F. Andacht, y F. Paulino (Eds.), Nuevos conceptos y territorios en América Latina (pp. 494-519).

Global Media Journal México, 18(34), 18-49, enero - junio 2021. 
Peña, L. (28 de noviembre de 2019). Un hijo: el mundo adentro y el corazón afuera. Juventud Rebelde. https://bit.ly/38HJaA6

Qva en Directo. (3 de enero de 2020). Cuba en Directo: ¿Qué pasó con Andy Vázquez? la Televisión Cubana responde... [Video]. YouTube. https://bit.ly/3hlNme0

Redacción Razones de Cuba. (13 de noviembre de 2019). Cinco verdades sobre Zoonosis y el maltrato animal en \#Cuba. Razones de Cuba. http://bit.ly/3tpKT4Y

Redacción Razones de Cuba. (14 de noviembre de 2019). Activistas por el bienestar animal en Cuba insisten en fortalecer su vínculo con el Estado. Razones de Cuba. https://bit.ly/2Sjz3MY

Redacción Digital Granma. (12 de octubre de 2019). Información del Ministerio de Salud Pública sobre casos asociados a proceso de vacunación en Habana del Este. Granma. https://bit.ly/3pAJp7a

Redacción Nacional Granma. (24 de diciembre de 2019). Desmiente Ministro de Economía cubano manipulaciones sobre un cambio monetario inminente. Granma. 2. https://bit.ly/3ze71BJ

Reese, S. D., y Danielian, L. H. (1989). Intermedia Influence and the Drug Issue: Converging on Cocaine. En D. L. Protess y M. McCombs (Eds.), Agenda Setting. Readings on Media, Public Opinion, and Policymaking (pp. 237-249). Routledge. https://bit.ly/3v5JalY

República de Cuba. (2019). Constitución de la República de Cuba. https://bit.ly/3cs5GPu

Rogers, E., y Dearing, J. W. (1988). Agenda-Setting Research: Where Has It Been, Where Is It Going? En J. A. Anderson (Ed.), Communication Yearbook (Vol. 11, pp. 555-594). Routledge. https://bit.ly/3zg0PKP

Salazar, S. (2017). Acercamiento al sistema de medios de comunicación en Cuba. Estudios Latinoamericanos, Nueva Época (39), 37-50. https://doi.org/10.22201/cela.24484946e.2017.39.58299

Schreier, M. (2012). Qualitative Content Analysis in Practice. SAGE.

Skilling, H. G. (1989). Samizdat and an Independent Society in Central and Eastern Europe. The Macmillan Press. Song, Y. (2007). Internet news media and issue development: a case study on the roles of independent online news services as agenda-builders for anti-US protests in South Korea. New Media \& Society, 9(1), 71-92. https://doi.org/10.1177/1461444807072222

Strodthoff, G. C., Hawkins, R. P., y Schoenfeld, A. C. (1985). Media Roles in a Social Movement: A Model of Ideology Diffusion. Journal of Communication, 35(2), 134-153. https://doi.org/10.1111/j.14602466.1985.tb02239.x

UNEAC. (10 de diciembre de 2019). UNEAC rechaza calumnias de Vargas Llosa. Cubadebate. https://bit.ly/350Lf87

Valdés, M. V. (31 de octubre de 2019). Cuba contra el bloqueo: No se detiene la vida en el hospital de Baracoa. Cubadebate. https://bit.ly/38Je3Ey

Global Media Journal México, 18(34), 18-49, enero - junio 2021. 
Valenzuela, S., Puente, S., y Flores, P. M. (2017). Comparing Disaster News on Twitter and Television: An Intermedia Agenda Setting Perspective. Journal of Broadcasting \& Electronic Media, 61(4), 615-637. https://doi.org/10.1080/08838151.2017.1344673

Wang, W., y Guo, L. (2018). Framing genetically modified mosquitoes in the online news and Twitter. Intermedia frame setting in the issue-attention cycle. Public Understanding of Science, 27(8), 937-951. https://doi.org/10.1177/0963662518799564

Whitney, D. C., y Becker, L. B. (1982). 'Keeping the Gates' for Gatekeepers: The Effects of Wire News. Journalism Quarterly, 59(1), 60-65. https://doi.org/10.1177/107769908205900109 